Volume: 2, Issue: 3, September 2017, Pages: 211-216, DOI: http://dx.doi.org/10.19082/ah211

\title{
EFFECT OF INTRAVENOUS IMMUNOGLOBULIN IN PREVENTION OF PRETERM NEONATAL SEPSIS: A CLINICAL TRIAL STUDY
}

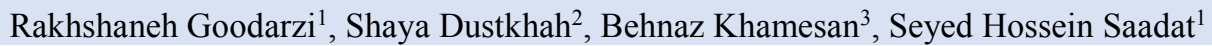

1: M.D., Assistant Professor, Neonatologist, Clinical Research Development Center of Children Hospital, Hormozgan University of Medical Sciences, Bandar Abbas, Iran

2: M.D., Pediatrics, Clinical Research Development Center of Children Hospital, Hormozgan University of Medical Sciences, Bandar Abbas, Iran

3: M.D., Pediatrics, Department of Pediatric, Khalij Fars Hospital, Islamic Azad University, Hormozgan University of Medical Sciences, Bandar Abbas, Iran

\section{TYPE OF ARTICLE: ORIGINAL ARTICLE}

\begin{abstract}
Background: The incidence of severe sepsis and septic shock is higher among preterm infants. Prevention of neonatal sepsis has remained a global challenge in recent decades. The role of intravenous immunoglobulin (IVIG) as an adjunctive treatment in sepsis has been shown in experimental and clinical trials.

Objective: The present controlled clinical trial was carried out with the objective of determining the effect of intravenous immunoglobulin in prevention of preterm neonatal sepsis.

Methods: This single-blind randomized clinical trial was performed in Hormozgan in Iran in 2015. Preterm neonates with low birth weight (LBW) were recruited in the study and were randomly divided into two groups. The intervention group received IVIG in addition to routine and general care, including antibiotic treatment, while the control group was given routine and general care without IVIG. IVIG was given to members of the intervention group at slow intravenous infusions at a dose of $500 \mathrm{mg} / \mathrm{kg}$ within $12 \mathrm{~h}$ and 3 days of birth, respectively. At the end of first week, two groups were compared for mortality rate, total number of days of hospitalization, incidence of intraventricular hemorrhage (IVH), necrotizing enterocolitis (NEC), and bronchopulmonary dysplasia (BPD). Statistical analysis was conducted by SPSS version 19 using means \pm standard deviation, number (\%), Chi-square test, and Independent-samples-t-test.

Results: A total of 92 infants were enrolled, 46 in intervention and 46 in control group. Administration of IVIG as an adjunctive treatment significantly improved the prevalence of sepsis $(0.0487 ; 95 \% \mathrm{CI}, 0.0027-0.8711, p$ value $=0.04)$ and $\mathrm{C}$-reactive protein $(0.1869 ; 95 \% \mathrm{CI}, 0.0380-0.9194, p$-value $=0.0391)$ in intervention group in comparison with the control group. No significant differences were observed in IVH, BPD, and NEC between the experimental groups ( $p$-value $>0.05$ ). Duration of hospitalization was $13.86 \pm 7.31$ days in IVIG group and 20.84 \pm 11.93 days in control group ( $p$-value $<0.05$ ).

Conclusion: Prophylactic IVIG is effective in reducing nosocomial infections and duration of hospitalization in preterm and LBW neonates, but has no effect on IVH, BPD, and NEC. We recommend prophylactic IVIG in preterm infants with LBW.

Trial registration: The trial is registered at the ClinicalTrials.gov with the identification number NCT02954926.

Founding: The authors received financial support from Research Deputy of Hormozgan University of Medical Sciences.

KEYWORDS: Intravenous immunoglobulin, Neonatal sepsis, Intraventricular hemorrhage, Necrotizing enterocolitis, Bronchopulmonary dysplasia
\end{abstract}

\section{INTRODUCTION}

Neonatal sepsis is a clinical syndrome characterized by systemic signs of infection and accompanied by bacteremia in the first month of life (1). Sepsis occurring in the first 72 hours of life is defined as early-onset sepsis (EOS) (2-4) and that occurring beyond 72 hours as late-onset sepsis (LOS) $(5,6)$. Newborns are relatively immunocompromised to deal with an infection due to the deficiencies in their humoral immunity. In addition, preterm neonates have

\section{Correspondence:}

Dr. Shaya Dustkhah, Clinical Research Development Center of Children Hospital, Hormozgan University of Medical Sciences, Bandar Abbas, Iran. Tel: +98.9129341830; Email: Shaya_doustkhah@yahoo.com

Received: January 17, 2017, Accepted: July 13, 2017, Published: September 2017

iThenticate screening: January 19, 2017, English editing: July 29, 2017, Quality control: August 5, 2017

(C) 2017 The Authors. This is an open access article under the terms of the Creative Commons Attribution-NonCommercialNoDerivs License, which permits use and distribution in any medium, provided the original work is properly cited, the use is non-commercial and no modifications or adaptations are made. 
decreased complement factors, opsonic activity, and polymorphonuclear chemotaxis and are more prone to such infections and further complications $(7,8)$. Therefore, the incidence of severe sepsis and septic shock is higher among preterm infants. Incidence of newborn infection accounts for high neonatal morbidity and mortality in most societies in spite of recent advances in intensive care. Thus, prevention of neonatal sepsis has remained a global challenge in the recent decades (9-13). In this regard, adjunctive sepsis treatment regimens to neutralize or antagonize endotoxin, presumptive antibiotic coverage, and sepsis mediators are the treatment of choice for infants with symptoms, signs, or risk factors of sepsis. However, their efficacy is still variable and limited.

On the other hand, the role of intravenous immunoglobulin (IVIG) as an adjunctive treatment in sepsis has been shown in experimental and clinical trials due to its positive effects on the infant's immune system (13-15). The pathophysiological causes for administration of IVIG composed of complement activation, neutralization of endotoxin and a wide variety of super-antigens, enhancement of opsonization and phagocytosis, and modification of endotoxin-released cytokines or mononuclear blood cells. However, the majority of healthcare authorities believe that, due to the methodological weakness and small number of patients in conducted therapeutic trials, the evidence remains insufficient to support the efficacy of intravenous immunoglobulin G (IVIG) in prevention of preterm neonatal sepsis (15-19). The present controlled clinical trial was carried out with the objective of determining the effect of intravenous immunoglobulin in prevention of preterm neonatal sepsis.

\section{MATERIALS AND METHODS}

\subsection{Study Design and setting}

This single blind randomized controlled trial was performed in pediatric hospital of Hormozgan Province in Iran in 2015. The hospital is the largest tertiary care pediatric center in the south of Iran. Parents of infants were informed about the aim of this intervention and probable side effects; after obtaining informed consent and institutional review board approval of Hormozgan University of Medical Sciences, they were randomly assigned to the control group and the intervention group.

\subsection{Participants}

Infants who were born alive before 37 weeks of pregnancy (preterm neonates) and infants under $2500 \mathrm{~g}$ at birth, low birth weight (LBW) infants, were recruited in the study. Patients underwent physical examinations at the screening visit by the neonatologist. Thereafter, demographic characteristics, history of related risk factors, and results of physical examinations were recorded for each participant in a pre-designed data collection sheet. Infants with lethal anomaly, congenital heart disease, TORCH infection, and severe asphyxia were excluded from the investigation.

\subsection{Diagnosis}

All of the infants underwent the diagnostic tests, including blood culture, complete blood count (CBC), and Creactive protein (CRP) estimation. The diagnosis of septicemia was confirmed by a positive blood culture or by clinical examinations with positive results of $\mathrm{CBC}$ and $\mathrm{CRP}$ tests.

\subsection{Interventions}

All of the infants underwent sepsis workup while admitted to the neonatal unit. The intervention group received IVIG in addition to routine and general care, including antibiotic treatment, while the control group was given routine and general care without IVIG. IVIG was given to members of the intervention group as slow intravenous infusion at a dose of $500 \mathrm{mg} / \mathrm{kg}$ within $12 \mathrm{~h}$ and 3 days of birth, respectively.

\subsection{Outcome}

At the end of first week, the reassessment of sepsis was carried out, and the findings were recorded. Comparison of mortality rate (due to sepsis or its associated complications), total number of days of hospitalization, incidence of intraventricular hemorrhage (IVH), necrotizing enterocolitis (NEC), and bronchopulmonary dysplasia (BPD) between two groups were considered as the outcome of treatment.

\subsection{Research Ethics}

A written informed consent was obtained from the parents of all study participants. The patients' information was kept confidential. The study is confirmed by the ethics committee of Hormozgan University of Medical Sciences (HUMS). ClinicalTrials.gov Identifier: NCT02954926. Ethical approval code was HUMS.REC.1394.162. 


\subsection{Statistical analyses}

Statistical analysis was conducted by SPSS version 19 (SPSS Inc, Chicago, IL, USA). The data are expressed as means \pm standard deviation and number (\%). Chi-square test was used to compare the categorical variables, and Independent-samples-t-test was used to compare continuous variables between the two groups. A two-sided $\alpha=0.05$ was considered statistically significant.

\section{RESULTS}

\subsection{Baseline characteristics}

Total 92 infants were enrolled, 46 in intervention and 46 in the control group, and no participants were excluded from the study during the research period (Figure 1). No statistically significant difference was reported based on age, gestational age, birth weight, and gender between the groups (Table 1).

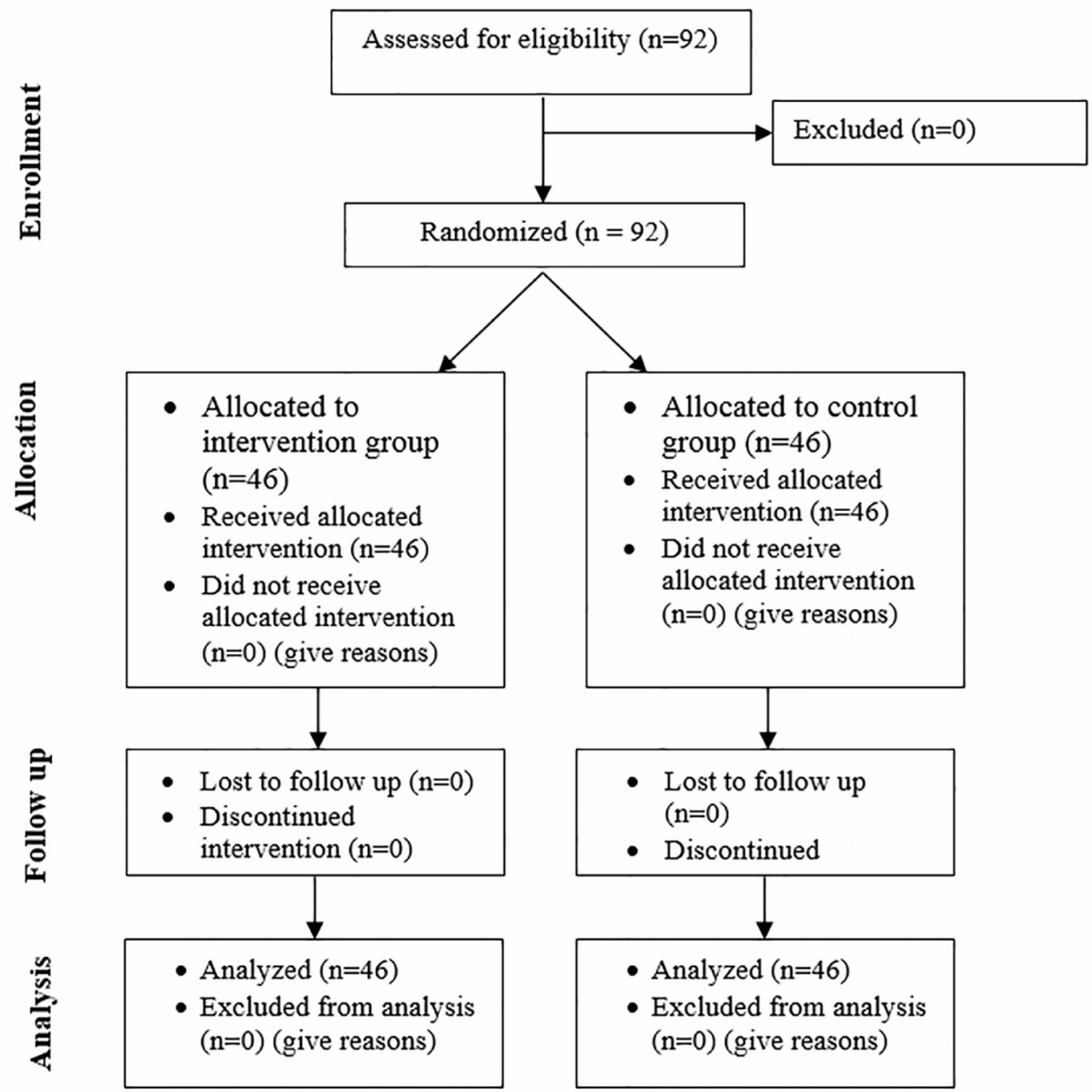

Figure 1: Flow diagram of the patients in the study

Table 1. Demographic and Baseline Characteristics of the Study Population

\begin{tabular}{|l|l|l|l|}
\hline Parameters, units & Intervention Group $(\mathrm{n}=46)$ & Control Group $(\mathrm{n}=46)$ & $\mathrm{p}$-value \\
\hline Age, days $($ mean \pm SD) & $8.53 \pm 2.32$ & $8.82 \pm 2.54$ & $\mathrm{P}>0.05$ \\
\hline Gestational age, weeks $($ mean \pm SD) & $32.12 \pm 1.47$ & $32.63 \pm 1.12$ & $\mathrm{P}>0.05$ \\
\hline Birth weight, kg $($ mean \pm SD) & $1.72 \pm 0.58$ & $1.64 \pm 0.36$ & $\mathrm{P}>0.05$ \\
\hline Gender, $\mathrm{n}($ male/female) & $24 / 22$ & $23 / 23$ & $\mathrm{P}>0.05$ \\
\hline
\end{tabular}




\subsection{Efficacy Parameters}

Administration of IVIG as an adjunctive treatment significantly improved the prevalence of sepsis $(0.0487 ; 95 \% \mathrm{CI}$, $0.0027-0.8711, p$-value $=0.040)$ and C-reactive protein $(0.1869 ; 95 \% \mathrm{CI}, 0.0380-0.9194, \mathrm{p}$-value $=0.0391)$ in intervention group in comparison with control group. Despite there being a decrease in the percentage of positive samples in intervention group, it is not statistically significant. No significant differences were observed in intraventricular hemorrhage, bronchopulmonary dysplasia, necrotizing enterocolitis, blood culture, and C-reactive protein between the experimental groups (Table 2). Duration of hospitalization was $13.86 \pm 7.31$ days in IVIG group and $20.84 \pm 11.93$ days in control group. The difference was statistically significant.

Table 2. Comparison of Study Variables Between the Experimental Groups

\begin{tabular}{|c|c|c|c|c|c|c|}
\hline \multicolumn{2}{|l|}{ Variables, n (\%) } & Intervention & Control Group & Odd & 95\% Confidence & p- \\
\hline Sepsis & $\begin{array}{l}\text { Positive } \\
\text { Negative }\end{array}$ & $\begin{array}{l}0(0 \%) \\
46(100 \%)\end{array}$ & $\begin{array}{l}8(17.4 \%) \\
38(82.6 \%)\end{array}$ & 0.04 & $0.0027-0.8711$ & $0.040^{*}$ \\
\hline $\begin{array}{l}\text { Intraventricular } \\
\text { hemorrhage }\end{array}$ & $\begin{array}{l}\text { Positive } \\
\text { Negative }\end{array}$ & $\begin{array}{l}6(13 \%) \\
40(87 \%)\end{array}$ & $\begin{array}{l}4(8.7 \%) \\
42(91.3 \%)\end{array}$ & 1.57 & $0.4136-5.9983$ & 0.505 \\
\hline $\begin{array}{l}\text { Bronchopulmonary } \\
\text { dysplasia }\end{array}$ & $\begin{array}{l}\text { Positive } \\
\text { Negative }\end{array}$ & $\begin{array}{l}0(0 \%) \\
46(100 \%)\end{array}$ & $\begin{array}{l}0(0 \%) \\
46(100 \%)\end{array}$ & 1.00 & $0.0194-51.4710$ & 0.999 \\
\hline $\begin{array}{l}\text { Necrotizing } \\
\text { enterocolitis }\end{array}$ & $\begin{array}{l}\text { Positive } \\
\text { Negative }\end{array}$ & $\begin{array}{l}0(0 \%) \\
46(100 \%)\end{array}$ & $\begin{array}{l}0(0 \%) \\
46(100 \%)\end{array}$ & 1.00 & $0.0194-51.4710$ & 0.999 \\
\hline Blood culture & $\begin{array}{l}\text { Positive } \\
\text { Negative }\end{array}$ & $\begin{array}{l}0(0 \%) \\
46(100 \%)\end{array}$ & $\begin{array}{l}3(6.5 \%) \\
43(93.5 \%)\end{array}$ & 0.13 & $0.0067-2.6627$ & 0.187 \\
\hline Death & $\begin{array}{l}\text { Positive } \\
\text { Negative }\end{array}$ & $\begin{array}{l}0(0 \%) \\
46(100 \%)\end{array}$ & $\begin{array}{l}0(0 \%) \\
46(100 \%)\end{array}$ & 1.00 & $0.0194-51.4710$ & 0.999 \\
\hline
\end{tabular}

\section{DISCUSSION}

In the present investigation, both groups were comparable for mean age, birth weight, gender, and mean gestational age. Findings of present trial revealed that administration of IVIG as an adjunctive treatment (in addition to standard therapy) reduced the prevalence of sepsis and its subsequent complications including C-reactive protein and positive blood culture. Also, based on our findings IVIG significantly reduced the duration of hospitalization. In accordance with our results, several authors indicated a significant improvement in the condition of septic infants given antibiotics plus IVIG in comparison with neonates given antibiotics but not treated with IVIG, identifying the beneficial role of IVIG as useful adjunctive therapy $(20,21)$. On the contrary, several trials have illustrated no impact of IVIG in treatment and prevention of neonatal sepsis in premature newborns. Therefore, a systematic review by Cochrane collaboration (2004) examined the association between IVIG therapy and treatment in premature and term infants. Although the evaluated studies were different in the dosing regimens, variety of IVIG products, and study populations, a significant reduction was observed in sepsis and its related complications (22). Recently, Cochrane updated its previous systematic review of IVIG for infection in infants with suspected or proven infection. Combining the findings of 10 documents carried out in eight countries revealed that sepsis and its complications reduced among neonates with clinically suspected infection and also subsequently proven infection (RR $0.58 ; 95 \%$ CI, 0.38 to 0.89 and RR $0.55 ; 95 \%$ CI, 0.31 to 0.98 ) (15). However, a recent large multicenter (113 sites), randomized, double blinded, placebo controlled study (13) evaluated the safety and efficacy of IVIG therapy in newborns. In a follow-up of 2-year-old infants, there were no significant differences in the rates of major or nonmajor disability or of adverse events, including the incidence of subsequent sepsis episodes (13). Finally, a systematic review by Ohlsson and Lacy (15) evaluated 26 studies for the role of IVIG in neonatal sepsis and its complications. The global effect of this outcome described that IVIG administration results in a significant reduction in sepsis and in one or more episodes of any serious infections (15). Findings of the present trial should be reported with caution because this study was limited in various ways. First, design of the present work was a single-blind randomised controlled trial, which elevated the bias in comparison with double-blind studies. Second, this is a single center study with limited patients and study population. Third, there was no case with necrotizing enterocolitis, bronchopulmonary dysplasia, and death in our investigation, which made us unable to compare the study groups in those variables. Therefore, it is suggested to consider these items in further investigations. 


\section{CONCLUSIONS}

Prophylactic IVIG is effective in reducing nosocomial infections and duration of hospitalization in preterm and LBW neonates but has no effect on IVH, BPD, and NEC. We recommend prophylactic IVIG in preterm infants with LBW. More studies should examine our hypothesis to confirm our results.

\section{ACKNOWLEDGMENTS:}

The paper is extracted from the results of thesis by Shaya Dustkhah, which has the requirements for abstaining the specialty degree in pediatric diseases. The authors want to thank the Clinical Research Development Center of Children Hospital, Hormozgan University of Medical Sciences, Bandar Abbas, Iran.

\section{CONFLICT OF INTEREST:}

The authors declare that they have no conflict of interests.

\section{FOUNDING:}

The authors received financial support from Research Deputy of Hormozgan University of Medical Sciences.

\section{AUTHORS' CONTRIBUTIONS:}

All authors contributed to this project and article equally. All authors read and approved the final manuscript.

\section{REFERENCES:}

1) Fehervari Z. Neonatal sepsis. Nat Immunol. 2016 May 19; 17(6): 617. PMID: 27196514. DOI: 10.1038/ni.3475.

2) Stoll BJ, Hansen NI, Sanchez PJ, Faix RG, Poindexter BB, Van Meurs KP, et al. Early onset neonatal sepsis: the burden of group B Streptococcal and E. coli disease continues. Pediatrics. 2011 May; 127(5): 817-26. PMID: 21518717. PMCID: PMC3081183. DOI: 10.1542/peds.2010-2217.

3) Oh W. Early onset neonatal group B streptococcal sepsis. Am J Perinatol. 2013 Feb; 30(2): 143-7. PMID: 23322392. DOI: $10.1055 / \mathrm{s}-0032-1332804$.

4) Ilboudo CM, Jackson MA. Early Onset Neonatal Sepsis and Meningitis. J Pediatric Infect Dis Soc. 2014 Dec; 3(4): 354-7. PMID: 26625458. DOI: 10.1093/jpids/piu003.

5) Resende DS, Peppe AL, dos Reis H, Abdallah VO, Ribas RM, Gontijo Filho PP. Late onset sepsis in newborn babies: epidemiology and effect of a bundle to prevent central line associated bloodstream infections in the neonatal intensive care unit. Braz J Infect Dis. 2015 Jan-Feb; 19(1): 52-7. PMID: 25523073. DOI: 10.1016/j.bjid.2014.09.006.

6) Yau KI. Prevention and control of neonatal sepsis. Acta Paediatr Taiwan. 2000 May-Jun; 41(3): 117-8. PMID: 10920541.

7) Gentile LF, Nacionales DC, Lopez MC, Vanzant E, Cuenca A, Cuenca AG, et al. Protective immunity and defects in the neonatal and elderly immune response to sepsis. J Immunol. 2014 Apr 1; 192(7): 3156-65. PMID: 24591376. PMCID: PMC3967513. DOI: 10.4049/jimmunol.1301726.

8) Kenzel S, Henneke P. The innate immune system and its relevance to neonatal sepsis. Curr Opin Infect Dis. 2006 Jun; 19(3): 264-70. PMID: 16645488. DOI: 10.1097/01.qco.0000224821.27482.bd.

9) Turhan EE, Gursoy T, Ovali F. Factors which affect mortality in neonatal sepsis. Turk Pediatri Ars. 2015 Sep; 50(3): 170-5. PMID: 26568693. PMCID: PMC4629925. DOI: 10.5152/TurkPediatriArs.2015.2627.

10) Lutsar I, Chazallon C, Carducci FI, Trafojer U, Abdelkader B, de Cabre VM, et al. Current management of late onset neonatal bacterial sepsis in five European countries. Eur J Pediatr. 2014 Aug; 173(8): 997-1004. PMID: 24522326. DOI: 10.1007/s00431-014-2279-5.

11) Ginsburg AS, Meulen AS, Klugman KP. Prevention of neonatal pneumonia and sepsis via maternal immunisation. Lancet Glob Health. 2014 Dec; 2(12): e679-80. PMID: 25433615. DOI: 10.1016/S2214109X(14)70317-1.

12) Brady MT, Polin RA. Prevention and management of infants with suspected or proven neonatal sepsis. Pediatrics. 2013 Jul; 132(1): 166-8. PMID: 23753101. DOI: 10.1542/peds.2013-1310.

13) Group IC, Brocklehurst P, Farrell B, King A, Juszczak E, Darlow B, et al. Treatment of neonatal sepsis with intravenous immune globulin. N Engl J Med. 2011 Sep 29; 365(13): 1201-11. PMID: 21962214. DOI: 10.1056/NEJMoa1 100441.

14) Franco AC, Torrico AC, Moreira FT, Sa FP, D'Elia HV, Bernardo WM. Adjuvant use of intravenous immunoglobulin in the treatment of neonatal sepsis: a systematic review with a meta-analysis. J Pediatr (Rio J). 2012 Sep-Oct; 88(5): 377-83. doi: PMID: 23002082. DOI: 10.2223/JPED.2218. 
15) Ohlsson A, Lacy J. Intravenous immunoglobulin for suspected or subsequently proven infection in neonates. Cochrane Database Syst Rev. 2010 Mar 17(3): CD001239. PMID: 20238315. DOI: 10.1002/14651858.CD001239.pub3.

16) Shaw CK, Thapalial A, Shaw $P$, Malla K. Intravenous immunoglobulins and haematopoietic growth factors in the prevention and treatment of neonatal sepsis: ground reality or glorified myths? Int J Clin Pract. 2007 Mar; 61(3): 482-7. PMID: 17313617. DOI: 10.1111/j.1742-1241.2006.01162.x.

17) Shenoi A, Nagesh NK, Maiya PP, Bhat SR, Subba Rao SD. Multicenter randomized placebo controlled trial of therapy with intravenous immunoglobulin in decreasing mortality due to neonatal sepsis. Indian Pediatr. 1999 Nov; 36(11): 1113-8. PMID: 10745332.

18) Jenson HB, Pollock BH. The role of intravenous immunoglobulin for the prevention and treatment of neonatal sepsis. Semin Perinatol. 1998 Feb; 22(1): 50-63. PMID: 9523399.

19) Jenson HB, Pollock BH. Meta-analyses of the effectiveness of intravenous immune globulin for prevention and treatment of neonatal sepsis. Pediatrics. 1997 Feb; 99(2): E2. PMID: 9099759.

20) Haque KN, Zaidi MH, Bahakim H. IgM-enriched intravenous immunoglobulin therapy in neonatal sepsis. Am J Dis Child. 1988 Dec; 142(12): 1293-6. PMID: 3195529.

21) Fischer GW, Hemming VG, Hunter KW, Jr., Gloser H, Bachmayer H, Von Pilar CE, et al. Intravenous immunoglobulin in the treatment of neonatal sepsis: therapeutic strategies and laboratory studies. Pediatr Infect Dis. 1986 May-Jun; 5(3 Suppl): S171-5. PMID: 3520501.

22) Ohlsson A, Lacy JB. Intravenous immunoglobulin for preventing infection in preterm and/or low-birthweight infants. Cochrane Database Syst Rev. 2004 (1): CD000361. PMID: 14973955. DOI: 10.1002/14651858.CD000361.pub2. 